\title{
A EDUCAÇÃO FÍSICA ENTRE MUROS E O IMPEDIMENTO DA EMANCIPAÇÃO DO SUJEITO*
}

\author{
THE PHYSICAL EDUCATION BETWEEN WALLS AND THE \\ IMPEDIMENT OF THE EMANCIPATION OF THE SUBJECT
}

\author{
Rogério Rodrigues \\ Universidade Federal de Itajubá - UNIFEI
}

\section{RESUMO}

Este estudo tem como objetivo analisar a educação do corpo diante da interdição dos espaços nas cidades onde se instaura o paradigma do muro. $\mathrm{O}$ tema encontra justificativa no modo de pensar o lazer e o planejamento urbano, de forma que se possa analisar as cidades enquanto espaço de emancipação ou alienação do sujeito. $\mathrm{O}$ método utilizado na pesquisa tem como proposição investigativa o campo da teoria crítica a ser aplicado na análise do conceito de educação física. Concluiu-se neste estudo que, ao se pensar a educação do corpo numa sociedade democrática, em todas as instâncias, é necessário levar em consideração a construção das cidades para que se possa romper com o paradigma do muro.

Palavras-chave: Educação. Educação do Corpo. Educação Física.

\begin{abstract}
This study aims to analyze the education of the body before the interdiction of spaces in the cities where the paradigm of the wall is established. The theme finds justification in the way of thinking about leisure and urban planning, so that one can analyze the cities as a space of emancipation or alienation of the subject. The method used in the research has as investigative proposition the field of critical theory to be applied in the analysis of the concept of physical education. It was concluded in this study that, in thinking about the education of the body in a democratic society, in all instances, it is necessary to take into account the construction of cities in order to break with the paradigm of the wall.

Keywords: Education. Body Education. Physical education.

\section{INTRODUÇÃO: A EDUCAÇÃO FÍSICA E O IMPOSSÍVEL NA RUPTURA DO PARADIGMA DOS MUROS}


O objetivo deste ensaio é colocar em evidências algumas indagações acerca da questão do muro e, principalmente, analisar suas interfaces entre corpo e cidade. Para tanto, trata-se em colocar evidencia o problema das contradições que se encontram presentes nas inter-relações entre o conceito de cidadania e a prática do lazer em cidades construídas a partir do paradigma dessas interdições físicas e simbólicas proporcionadas pelo muro. Para discutir essa questão, o método utilizado tem como proposição investigativa o campo da teoria crítica para analisar o conceito de lazer em interface com a educação física e a cidade. ${ }^{1}$

Quando se fala em educação física, o pensamento mais recorrente em relação a isso são as atividades curriculares realizadas conscientemente entre os muros da escola, sob supervisão do educador físico, que possui a estranha tarefa de transmitir as técnicas corporais (MAUSS, 1974). O estranhamento deve-se ao fato de que todos nós usamos o corpo de um modo peculiar, enquanto alguém na condição de educador apresenta outro modo de usar o corpo, de forma que atenda aos critérios do rendimento na disciplina que impõem ao sujeito.

Neste ensaio, trabalhar-se-á outro conceito de educação física, aquele que se encontra em outro conjunto de significados do uso do corpo, em outro "entre muros", seria o modo peculiar como somos educados consciente e inconscientemente para usar os nossos corpos em cidades construídas a partir do paradigma do muro, a expressão do conceito de propriedade privada e contenção do medo do contato com o outro (CANETTI, 1985). Em termos de propriedade privada, os espaços são restritos àqueles que se encontram autorizados à circulação de seus corpos. Em relação ao medo do contato, o outro, em sua alteridade, promove um desconforto numa sociedade que se preserva sob a forma do narcisismo, em que a semelhança é atributo de conciliação e amizade.

Para se analisar a educação física entre muros, partimos da hipótese de que isso é algo que também se encontra diretamente relacionado às cidades, que são construídas e representadas para os sujeitos circularem em espaços prédeterminados, em decorrência das interdições físicas e simbólicas que se expressam na noção de propriedade privada, ou ainda se apoderarem dos territórios que se estruturam no medo do contato com o outro.

\footnotetext{
${ }^{1} \mathrm{O}$ termo "educação física" está sendo usado de modo genérico referente como se realiza a educação do corpo no estilo de vida do sujeito no interior das cidades.
} 
No que diz respeito a essas produções territoriais, a administração pública deveria intervir no sentido de tornar o espaço público algo comum a todos. Contudo, o que se produz na maioria das vezes são formas de privatizar o que é público e isso se representa sob a forma de se pensar acerca de várias questões a respeito da cidade, como o modo por meio do qual os espaços urbanos são representados, como não pertencentes à coletividade.

O planejamento urbano seria algo condizente a se fazer em termos de estudo, para que se possa construir as cidades como um espaço que se relacione com a necessidade de circulação dos sujeitos, num viés de tornar o espaço público algo pertencente a todos e, portanto, favorável aos processos de emancipação do sujeito. Todavia, apesar de as cidades possuírem o planejamento cartesiano, a execução em seus resultados se apresenta de modo aleatório, uma vez que as cidades são mais um amontoado de partes que não se encaixam, apesar de toda a engenharia que as envolve suas construções, tornamo-nos sujeitos pertencentes às cidades no paradoxo do não pertencimento, mesmo estando completamente alienados ao espaço.

$\mathrm{Na}$ ausência de concepção do planejamento dos espaços públicos como representação de pertencimento a todos, como um saber comum do "não sabido", há como resultado o inverso do que seria o projeto de cidade, algo que girasse em torno da hegemonia, cujos muros circunscrevessem o paradigma por onde os corpos pudessem e devessem circular, ou espaços que devessem ser interditados para a livre circulação de pessoas.

O espaço público é representado como não pertencente a todos e, dessa forma, em nossa atualidade, o uso do muro se torna cada vez mais corriqueiro, fechando inclusive os espaços públicos, tornando-os restritos ao uso particular. Quando não há o muro físico, constituem-se outras barreiras que promovem a mesma interdição que impede a passagem do sujeito de um lado para o outro, como a presença de regras que interditam pessoas comuns e não autorizadas.

A ideia de muro nas cidades apresenta-se como uma invenção antiga na história da nossa humanidade, como um dispositivo de defesa aos ataques do outro. As cidades muradas como, por exemplo, a cidade de Óbidos (Portugal) apresenta-se como modelo de proteção, como fortificações para evitar o outro, e isso se espalhou por diversos lugares do planeta (FOLHA, 2018). Entretanto, atualmente, essa contingência dos espaços produz seus efeitos e adquirimos maneiras específicas de fazer uso dos nossos corpos como marcas da sociedade em que vivemos, e os muros 
podem representar as demarcações de exclusão social, uma vez que interditam as possibilidades de acesso do outro a espaços que não lhe pertence devido ao seu segmento social. Portanto, os indivíduos são educados por diversas proposições de barreiras físicas e sociais que se incorporam no modo de ser sujeito, no conjunto das técnicas corporais (MAUSS, 1974) que se apresentam como uma verdadeira educação física entre muros.

Desde o nascimento do sujeito, este se encontra num trabalho permanente de aprendizagem de diversas técnicas corporais que se constituem na maneira específica de cuidar de si. Com o passar dos anos, esses cuidados se tornam modos de usar o corpo e de representação do sujeito natural como pertencente e independente da cultura. Nessa oposição entre natureza e cultura, pouco se busca saber sobre a passagem do corpo para posição de caminhar em pé, algo fundamental para a criança e, primordialmente, uma verdadeira conquista para toda espécie humana, em sua transformação nos modos de ver e sentir o mundo. Para Freud (1996), essa passagem é crucial para a espécie humana e ele a interpreta como a ontogênese do sujeito, uma vez que este incorpora em si mesmo elementos do processo civilizatório ao distinguirse dos animais, pois

\begin{abstract}
A própria diminuição dos estímulos olfativos parece ser consequência de o homem ter-se erguido do chão, de sua adoção de uma postura ereta; isso tornou seus órgãos genitais, anteriormente ocultos, visíveis e necessitados de proteção, provocando desse modo sentimentos de vergonha nele. O processo fatídico da civilização ter-se-ia assim estabelecido com a adoção pelo homem de uma postura ereta (FREUD, 1996, p. 105).
\end{abstract}

Sobre essa educação física de corpo que nos torna sujeitos no processo civilizatório, ela é que nos permite pensar se isso seria realmente algo peculiar à história da nossa espécie, mas com um elemento contraditório, uma vez que basta um simples caminhar pelas ruas para que se torne evidente que as cidades estão trancadas e anula a representação do sujeito, o que resulta num estado de regressão a uma concepção de mundo em que a vida não possui valor.

Essa falta de representação da existência do sujeito ou da perda da experiência de vida tornou as cidades hegemonicamente uma arquitetura de muros para todos os lados, como impedimento do contato físico com o outro, como representação de intolerância perante a diferença, pois tudo o que manifesta a vida promove certa repugnância e desconforto para aqueles que, no processo civilizatório, representam a si mesmo e o outro como objeto. Para Adorno (1986), 
O amor-ódio pelo corpo impregna toda a cultura moderna. O corpo se vê de novo escarnecido e repelido como algo inferior e escravizado, e, ao mesmo tempo, desejado como o proibido, reificado, alienado (ADORNO, 1986, p. 217).

Essa ambivalência em relação ao corpo torna-se uma chave para se compreender esse paradigma dos muros que educam os sujeitos fisicamente no modo de usar seus corpos, numa relação de funcionamento que simultaneamente estabelece uma mecânica de incluir e excluir. Portanto, o dispositivo do muro torna próximo e protegido quem está dentro e, ao mesmo tempo, torna o outro afastado e repelido de quem está do lado de fora. Para compreender esse duplo mecanismo do muro como dispositivo, é necessário observar em alguns detalhes como isso ocorre em qualquer espaço público ou privado como forma de expressão do sentimento de igualdade ou dessemelhança perante o outro, ou ainda como expressão de domínio na demarcação de território, numa concepção de posse pautada na ideia de propriedade privada plenamente constituída em termos jurídicos e sociais, numa educação física que torna impossível a ruptura do paradigma dos muros para construção de espaços que possam permitir a emancipação do sujeito na constituição de formas de partilhar o sensível, que seria

[...] o sistema de evidencias sensíveis que revela, ao mesmo tempo, a existência de um comum e dos recortes que definem lugares e partes respectivas. Uma partilha do sensível fixa portanto, ao mesmo tempo, um comum partilhado e partes exclusivas. Essa repartição das partes e dos lugares se funda numa partilha de espaços, tempos e tipos de atividade que determina propriamente a maneira como um comum se preta à participação e como uns e outros tomam parte nessa partilha (RANCIÈRE, 2009, p. 15).

Nesse sentido, pensar a educação física entre muros é colocar em questão o modo como as cidades são construídas, como os muros estabelecem um desenho de partilha do sensível em lugares em que se pode circular e em diversos lugares em que não se pode adentrar, assumindo uma forma de restrição nos processos formativos que alcançam as dimensões no uso do corpo e impedimento do lazer como forma de representação do embrutecimento do uso do tempo livre.

\section{Resultados - O impossível em se pensar uma cidade sem muros como condição da emancipação dos sujeitos}


A questão do muro torna-se um elemento contraditório, uma vez que nos protege de algo inesperado e nos garante uma representação de segurança. Outra função colaborativa do muro é a proporção do conforto térmico que nos garante a condição de enfrentar as variações climáticas. Entretanto, temos o muro que serve para demarcar a propriedade e aqueles que instauram simbolicamente que se impõe em diversos espaços que nos faz chegar ao resultado de que estamos inseridos numa sociedade que não sabe pensar as cidades sem a presença inteligente do muro e, portanto, o reduz como instauração da barreira física e simbólica como elemento de segregação social.

Essa condição de interdição constituída pelos muros indica a ausência do pensamento crítico e se apresenta como um ponto cego (ADORNO, 1986) que favorece uma determinada lógica política em seu uso, numa interpretação do que seria a vida em cidade e como se deve circular por esses espaços e seus contornos. Dir-se-ia que os sujeitos desaprendem a ter o livre acesso ao espaço e, portanto, geram uma demanda de algo que os conduzam por onde circularem e, principalmente, por onde possam se realizar como aqueles que consomem para se tornarem felizes por estar em uma atividade de lazer, em oposição àqueles que supostamente se encontram com os seus corpos entre muros.

Pensar o sujeito na interface com o muro na constituição de si mesmo determina uma compreensão de educação física e, neste caso em específico, na prática do lazer. A identificação de que os sujeitos habitam cidades muradas leva à compreensão da importância de se perguntar acerca do medo primordial do homem ao buscar refúgio nesses tipos de construções arquitetônicas de muros que delimitam os espaços físicos. Para Canetti (1995) o medo é consequência do temor pelo contato, para evitá-lo:

[...] as pessoas trancam-se em casas que ninguém pode adentrar, somente nelas sentindo-se mais ou menos seguras. O medo do ladrão não se deve unicamente a seu propósito de roubar, mas é também um temor ante seu toque súbito, inesperado, saído da escuridão. A mão transformada em garra é o símbolo que sempre se emprega para representar esse medo (CANETTI, 1995, p.13).

No caso específico do muro, pode-se interpretá-lo como expressão da subjetividade do medo do contato, o que resulta na objetividade da instauração de barreiras físicas como projeto arquitetônico do isolamento, que se constitui no sentimento de segurança ou domínio do território que contorna as cidades, incluindo 
a semelhança e excluindo a diferença. Isso acaba por definir os espaços de circulação dos corpos e torna possível uma dupla aproximação em relação à educação física: de um lado, como o senso comum interpreta e explica o muro como modo de evitar a presença do outro no espaço público e, de outro lado, como a consciência crítica não consegue avançar nessa questão do medo do contato, pois isso se representa como ponto cego sobre outras possibilidades de arquitetura nas cidades, onde os diversos espaços poderiam ficar abertos para circulação dos sujeitos sem a construção de muros.

Em relação ao espaço urbano, pelo viés do senso comum, é impressionante a capacidade de se construir toda uma tecnologia do muro com o propósito de sentir-se seguro internamente em sua habitação. Entretanto, essa noção de murar-se não leva em consideração que nessas habitações os indivíduos são invadidos pelas diversas mídias que desenham em suas mentes a representação de mundo e o modo de fazer coisas, um exemplo dessa concepção pode ser observado na obra Casa Furada, que é inspirada em Vilém Flusser (1920-1991), em que fica representado que os sujeitos não são mais protegidos em suas habitações, pois na instalação visitada é possível observar um

[...] reduto da intimidade que ora não mais nos protege do mundo. Ele perfaz o que Flusser chama de "terceira catástrofe da humanidade", precedida por duas outras, a do bipedismo e a da sedentarização. Na casa com janelas e portas lacradas, aparentemente segura do ambiente externo, uma sala branca, um pouco suja, e excessivamente iluminada, tem suas paredes preenchidas por dezenas de telas novas e antigas de TV, além de aparelhos celulares ligados, furos e espelhos de tomadas, por onde o ambiente é invadido pela "ventania da informação e o furacão da mídia" (SESC, 2018).

Por outro lado, no campo dos intelectuais, torna-se evidente a ausência de reflexão da consciência crítica que se constitui como falta de reação a todo meio social murado que contamina todo o social, na compreensão de que construir barreiras físicas torna as vidas mais seguras. Aqui, toda a falta de palavras sobre o significado do paradoxo do muro se representa com a questão com a ausência em dizer algo, pois

O "ver" e o "fazer ver" se correspondem, embora não se identifiquem com o "falar" e o "fazer falar". A distribuição histórica do que se vê e do que se oculta vai em paralelo com a distribuição do que se diz e do que se cala. O visível vai em paralelo com o dizível. As formas legítimas de olhar se relacionam com as formas legítimas do dizer (LARROSA, 1995, p. 65). 
Desse modo, parte-se da hipótese de que a cidade entre muros institui uma concepção de educação física como forma de ver, fazer e dizer os diversos modos de lazer no campo da cultura que se impõem no campo do movimento corporal humano. No entanto, tudo indica que o ponto cego (ADORNO,1986) na questão do muro se representa numa anulação do lazer nas cidades, pois ocorre a ocupação do tempo livre na relação paradoxal de se constituir o tempo ocupado para encontrar espaços da educação física entre muros para realização da atividade recreativa.

Em relação ao ponto cego na questão do muro, isso se representa em termos críticos, como a expansão do paradigma do espaço urbano delimitado e pautado numa concepção do condomínio completamente murado. É muito pertinente observar que a cidade de São Paulo (Brasil) gira em torno do Shopping Center como lugar desencontro entre os sujeitos que consomem a diversão e o lazer num lugar que nada mais é que um condomínio de lojas. É oportuno observar que o hábito de passear em praças públicas foi substituído pelo passeio no interior desses ambientes de consumo entre muros.

Nesses espaços de consumo, o tempo não passa, pois a maioria dessas construções encontra-se completamente iluminada artificialmente, dia e noite se confunde, no sentido de se ampliar o tempo de consumo. Esses espaços possuem uma arquitetura que olhando de cima lembra uma caixa de sapato hermeticamente fechada. Sobre a expansão desses lugares fechados e sem luz natural, o urbanista Peter Marcuse constata que "São Paulo é a cidade com mais muros por metro quadrado do mundo" (MACHADO, 2018, p. 6).

Nesse modelo urbano de condomínio murado que se adota em grande parte das cidades só entram aqueles que não produzem estranhamento e que consomem, trabalham ou habitam os referidos espaços, ou seja, aqueles pertencentes à mesma classe social.

A visibilidade dos muros alimenta a construção de outros muros como uma forma de se evitar o medo ou o furto de materiais e equipamentos. O paradoxo dessa situação é que se tranca um espaço público para se evitar o outro, mas ao mesmo tempo se apresenta uma demanda pelo outro presente no espaço para a realização da atividade, assim, questiona-se: em qual lugar essa demanda por espaço de lazer se constitui nas cidades trancadas pelos muros?

No que diz respeito à educação física entre muros como impedimentos da expressão do sujeito têm diversos espaços na cidade que se encontram cercados com 
muros e cercas. Isso parece algo muito esquisito quando se trata de espaço público, mas essas formas de interdições se tornam comuns e os muros passam ser algo natural na vida de todos os intelectuais e gente comum da sociedade.

Por algumas vezes a questão do muro se apresenta como uma discussão estética, como exemplo dessa situação tem o muro da raia da USP, que em 2017 a administração do lugar fez a opção de trocar o muro de concreto, que separa a raia da Marginal Pinheiros, por um muro de gradil de ferro, no valor de três milhões de reais, afirmando que isso seria importante para a integração entre a cidade e a universidade (REDAÇÃO, 2018). O mais espantoso na referida proposta seria a retirada do muro de concreto para colocar grades para que a população que passa na Marginal Pinheiros, com velocidade máxima em seus automóveis, pudesse interagir com a universidade.

Foi analisado e constado que o muro de concreto evita que o nível de poluentes dos automóveis contamine o ar dos praticantes do remo na raia que fica ao lado da marginal do rio Pinheiros, numa extensão de $2 \mathrm{~km}$. A saída, para aqueles que apresentam o ponto cego para essa questão, foi a proposição de algo que permita a visibilidade, mas impeça a circulação da poluição para dentro da raia de remo, a resposta para esse problema foi construir um muro de vidro. Atualmente, tal obra se encontra em construção, com o custo aproximado de quinze milhões de reais (quatro milhões de euros). $\mathrm{O}$ fato impressionante é que não se encontra nenhuma manifestação contrária a essa produção (GLOBO, 2018b).

Torna-se importante destacar que a construção do novo muro de vidro vai invadir o espaço de lazer da raia de remo em torno de quatro metros, numa extensão de dois mil metros, e isso representa uma perda total de espaço de lazer de oito mil metros quadrados, ou seja, uma perda considerável no espaço de lazer para o mundo dos automóveis no impossível em se pensar uma cidade sem muro

\section{Discussão: a educação e o lazer em cidades construídas na impossibilidade de rupturas dos muros}

Como se torna possível pensar o uso do corpo na prática do lazer em cidades que circunscrevem as sociedades organizadas no cerceamento como forma de se evitar o contato com o outro? 
Para responder a essa questão, vamos partir da análise de três circunstâncias distintas como propostas de lazer presentes no Brasil, mas que se encontram circunscritas por barreiras físicas e sociais, isto é, formas de se utilizar o tempo livre na prática do lazer, a partir das expressões comuns que circulam no imaginário do social na interface dos sujeitos e na restrição do espaço público.

A primeira proposta é "a praia é para todos" a segunda é "a rua é nossa e vamos pedalar", e a terceira seria concepção de que "andar faz bem para a saúde”. Nessas três concepções de lazer, no campo do senso comum, ocorre uma resignificação dos espaços das cidades, e esses elementos são analisados como proposição de estudos que se encontram inseridos em áreas de pesquisas multidisciplinares.

Neste contexto, busca-se evidenciar de que forma o modo de vida dos sujeitos em cidades muradas viabiliza ou impede a possibilidade da expressão da cidadania, em se tratando do acesso às condições da prática do lazer - educação física entre muros. Assim, o tema deste ensaio insere-se na discussão das relações entre corpo e cidade, que se encontra hegemonicamente estabelecida numa concepção de mundo instrumental e pouco compreendida: "[...] palco da imbricação adensada das heterogeneidades materiais e imateriais da natureza e da sociedade" (FLORIANI, 2011, p. 364).

O uso técnico do corpo na prática do lazer encontra-se restrito a dois aspectos, quais sejam: o saber usar tecnicamente o corpo e o acesso a territórios para realização da prática corporal. A pergunta central é se teríamos outras possibilidades de relações entre corpo e cidade que pudessem resultar numa concepção crítica para além da relação de causa e efeito do uso técnico do corpo em relação ao lugar estabelecido para prática corporal.

Os elementos objetivos e subjetivos apontam para a hipótese de que as cidades não foram feitas para os sujeitos circularem amplamente com seus corpos em aspectos efetivamente democráticos. Basta andar e observar as dificuldades que se apresentam em nossas calçadas para a livre circulação dos sujeitos. Para aqueles que possuem alguma deficiência física, torna-se praticamente impossível a mobilidade urbana e, para aqueles que possuem a condição física inalterada, torna-se um verdadeiro risco caminhar pela cidade.

Isso se representa como uma recusa aos corpos circulando pelas ruas e praças interditadas por grades. O que prevalece como elemento que circula nas cidades são 
carros, como produção de máquinas de mobilidade urbana, e se os corpos não se desviarem, serão atropelados, mesmo que estes estejam circulando em espaço exclusivo para o pedestre.

Essa falta de urbanidade interfere nas três proposições supracitadas de lazer na educação física entre muros em análise. Todas elas, sendo expressões do senso comum para a realização das práticas corporais, perdem o sentido quanto à integração entre o sujeito e o espaço e, principalmente, entre os próprios sujeitos.

Na ideia de que "a praia é de todos”, no município da Praia Grande (Brasil), que fica no Estado de São Paulo, é impressionante a concentração de pessoas, em finais de semana, aumenta a população local em até quatro vezes, algo em torno de 272 mil pessoas, chegando a aproximadamente um milhão de indivíduos que se aglomeram na orla da praia (PREFEITURA PRAIA GRANDE, 2018).

Nessa massa de pessoas que se concentram na praia, no município da Praia Grande, ocorre o fenômeno do muro invisível: o quartel do exército brasileiro traçou, no canto direito da praia, uma linha imaginária que impede a circulação de pessoas nesse único e restrito espaço vazio. Há um soldado sentado numa cadeira e, toda vez que um banhista atravessa a linha imaginária, o soldado apita e pede para que este se retire. O que impressiona nesse muro invisível é que a massa de banhistas que se concentra nessa praia atende de modo obediente ao chamado do soldado, não ultrapassando o espaço demarcado.

Na segunda proposição, "a rua é nossa e vamos pedalar", seria uma proposta interessante de lazer se os gestores dessa prática tivessem algum senso crítico no modo de ocupar as ruas. O primeiro elemento crítico dessa situação é reconhecer que, infelizmente, as cidades foram projetadas exclusivamente para circulação de carros. No município de Santo André (Brasil), também no Estado de São Paulo, todo domingo, a prefeitura faz uma faixa de muros de cones, reservando um espaço especialmente para bicicletas numa via central, o que gera certo estranhamento, pois de um lado, há uma fila enorme de carros, e do outro lado, um vazio completo, sem ninguém andando de bicicleta. Quando passa um ciclista nessa via exclusiva, além de este estar consumindo uma quantidade considerável de monóxido de carbono, devido à alta concentração de veículos no trânsito, ele também se encontra numa situação de risco. O muro de cones, na demarcação da via especial para bicicleta, em nada protege o ciclista no caso de algum carro se desgovernar, como foi o caso do rapaz que pedalava em via restrita para bicicleta, na Avenida Paulista, na cidade de São 
Paulo (GLOBO, 2018a), que sofreu um atropelamento. A pergunta que se faz é: por qual motivo o pedalar de bicicleta ocorre em espaços de alta concentração de veículos?

A terceira proposição seria concepção de que "andar faz bem para a saúde", o que vai de encontro ao fato de que nas cidades não há espaço público para o pedestre caminhar, como é o caso extremo do município de Diadema (Brasil), também no Estado de São Paulo. Essa opção de lazer ocorre num redondo em que as pessoas ficam andando em círculo, contornadas pelo muro de carros. Cada volta completa nesse contorno de carros possui aproximadamente 150 metros e ninguém pode sair desse confinamento sem o risco de atropelamento por algum automóvel.

Essa condição de confinamento faz lembrar o filme "Expresso da meia-noite" (PARKER, 1978), no qual há uma cena muito marcante sobre os perigos de contrapor-se ao movimento das massas. O personagem principal do filme encontrase encarcerado e, na atividade do caminhar dos presos, como de costume, todos se exercitam andando no mesmo sentido em volta de uma grande coluna de concreto. Num momento, ele resolve andar no sentido contrário e, ao fazer tal coisa, promove entre todos uma revolta generalizada, ficando impedido de prosseguir, pois acaba sendo arrastado pela massa de presos que não tolera essa diferença. Na sociedade contemporânea, representa-se também na intolerância a pequena diferença, ou o que Freud (1996) denomina "narcisismo das pequenas diferenças" (FREUD, 1996, p. 119), que seria algo que não se resolve em palavras. Talvez o muro seja uma solução antiga, uma vez a distância que um sujeito fica do outro não permite apresentá-lo em toda sua existência e visibilidade.

\section{CONCLUSÃO - POR UMA CIDADE QUE PROMOVA A EMANCIPAÇÃO DO SUJEITO USO DO CORPO}

Ao se pensar acerca do processo de de/formação do sujeito em relação às questões do uso técnico do corpo, dever-se-ia encontrar elementos que pudessem romper com a concepção da competência técnica e neutra para uma posição de igualdade de acesso aos espaços nas cidades e para o pleno reconhecimento da desigualdade do interdito pelo muro, que se manifesta no impedimento da compreensão e do aceite da circulação dos corpos por lugares restritos, o que faz os sujeitos compreenderem o mundo a partir dessa experiência vivida. Isso implica,

@rquivo Brasileiro de Educação, Belo Horizonte, v. 9, n. 18, 2021 
como ponto de partida, em analisar a questão da qualidade no uso técnico do corpo na prática do lazer, no sentido de produzir políticas de gestão pública radicais na escolha do planejamento de qual tipo de cidade se pretende construir para o pleno acesso ao lazer.

Em termos de análise das interações entre cidade e corpo, este estudo indica que esse fenômeno do excesso de muros nas cidades deixa transparecer o elemento contraditório do conceito de cidadania, que indica uma falta de combinação ou não interação entre o modo de existir dos sujeitos e os espaços destinados à prática do lazer nas cidades muradas - a educação física entre muros como impedimento do lazer. Esse paradoxo se constitui na presença do muro, pautado na ideia da segurança e da inclusão da prática de atividades de lazer em cidades que se tornam constituídas numa representação que também possui como resultado a exclusão do outro.

Nesse ponto, tanto os muros como a competência técnica e neutra podem ser interpretados como eixo estruturante na formação do sujeito que se aliena e se embrutece perante a lógica de que

[...] não é qualquer um que pode em qualquer lugar e em qualquer ocasião dizer qualquer coisa a qualquer outro. $\mathrm{O}$ discurso competente determina de antemão quem tem o direito de falar e quem deve ouvir, assim como predetermina os lugares e as circunstâncias em que é permitido falar e ouvir, e, finalmente, define previamente a forma e o conteúdo do que deve ser dito e precisa ser ouvido [...] Em uma palavra, a ideologia da competência institui a divisão social entre os competentes, que sabem, e os incompetentes, que obedecem (CHAUI, 2016, p. 187).

Sendo assim, vivemos em cidades em que não ocorre a partilha do sensível (RANCIÈRE, 2009), em que o fazer, o circular, o sentir, enfim, todos os elementos que nos tornam sujeitos, constituem-se numa hegemonia da reificação das relações humanas e nos tornam restritos a uma educação física entre muros como impedimento do lazer e desse modo nas diversas práticas sociais:

A partilha do sensível faz ver quem pode tomar parte no comum em função daquilo que faz, do tempo e do espaço em que essa atividade se exerce. Assim, ter esta ou aquela "ocupação" define competências ou incompetências para o comum (RANCIÈRE, 2009, p. 16).

Em relação à não existência da partilha do sensível, isso se refere à prevalência da arquitetura dos muros, que cada vez mais se intensifica em todos os espaços. No caso específico da unidade escolar, isso permite o questionamento: seriam todas 
essas grades, cercas e muros para os sujeitos não entrarem ou para não saírem da escola?

Para além da aparência, ocorre a intenção política do uso do muro como interdição dos espaços, que seria a intenção política de toda essa arquitetura que se instaura numa sociedade que circula em torno do medo do contato com o outro como modo de controle e subordinação das inteligências, num processo de embrutecimento, pois “[...] há embrutecimento quando uma inteligência é subordinada a outra inteligência” (RANCIÈRE, 2002, p. 31).

Compreende-se que o muro, numa sociedade embrutecedora, segrega e, numa sociedade emancipadora, protege para a garantia da vida. Contudo, de um lado ou de outro, a sua estética não produz o agenciamento do encantamento (GUATTARI, 2000), pois sua totalidade transparece o impedimento da livre circulação dos sujeitos e pode representar, em traços concordantes, o segregar e o proteger, numa arquitetura em que a beleza encontra-se impedida pela realização do corte do olhar para o horizonte. É isso, talvez, uma tentativa de encontrar o horizonte perdido que se encontra espalhado pelos diversos muros pichados e grafitados das cidades dos países periféricos, como o desespero da busca por outra estética do embelezamento instituída em nossa modernidade.

Tudo indica que o muro vem a responder à constituição do real, sem nenhum tipo de encantamento, na lógica do mercado que se apresenta na disputa de ocupação de área pelas gangues e é atravessado pela violência das periferias, que também invade o centro das grandes e pequenas cidades. $O$ real das cidades é a expressão da exploração do capital, que, em seus iluminados outdoors, convida a todos para o consumo. Nesse caso, já convivemos harmonicamente com muros em que são desenhados "riscos e rabiscos" como forma de elementos de oposição à estética do outro olhar, que podem promover outros significantes nessas barreiras físicas, como uma tela que se expressa na arte que possa favorecer sua compreensão do real no conjunto das sínteses das múltiplas determinações (MARX, 1983).

Pode-se constatar que todos os espaços são invadidos pela tecnologia dos muros como discurso científico hegemônico, e alguns conceitos tornam-se recorrentes, como por exemplo: uma sociedade sem muro para inclusão, uma fábrica com muro para o rendimento, a escola entre muros para aprendizagem, as fronteiras de um país com muro para o desenvolvimento, e tantos outros que giram em torno da condição de interpretar as interfaces entre o sujeito e o muro. 
Geralmente, tais formulações inovadoras apresentam-se como adequações tendo paradoxalmente como resultado o embrutecimento em de/formar o sujeito como objeto manipulável acrítico e não participativo. Sempre se deveria ficar em dúvida sobre como se torna possível constituir na formação do sujeito crítico e participativo, pois o que se apresenta como modelo de sistema econômico e social coloca em questão a vida sustentável do próprio planeta, portanto

O conjunto da divisão do trabalho, seus modos de valorização e suas finalidades devem ser igualmente repensados. A produção pela produção, a obsessão pela taxa de crescimento, quer seja no mercado capitalista ou na economia planificada, conduzem a absurdidades monstruosas. (GUATTARI, 2000, p. 33).

Assim, podem-se observar diversos aspectos daquilo que se denomina processo formativo no campo da educação física como algo para tornar o sujeito produtivo na realização de "máquinas totalitárias capitalistas" (GUATTARI, 2000). Novamente, coloca-se a questão: seria possível a tentativa de reelaborar esses conceitos hegemônicos dos muros em nossa sociedade em outra ordenação simbólica para emancipação do sujeito e, portanto, em corpos livres de circulação pelos espaços das cidades?

Para tanto, inicia-se e termina-se essa questão do muro e a educação física tentando compreender, em território específico, a interdição dos espaços, uma determinada reinterpretação dos muros, tendo como base a crítica do senso comum que o compreenda somente como resultado da perda de espaço numa falta da competência técnica de gestão pública.

Seria oportuno identificar nesses elementos o paradoxo de que a interdição dos espaços é a grande competência da gestão pública, que torna senso comum o impossível, as rupturas e a reelaboração daqueles que, por destino de vida, produzem um conjunto de construções de muros que podem servir de indicativos para avaliar os impossíveis caminhos da oposição singular do sujeito perante o capital, que tenta encontrar outros modos de expressar sua engenhosidade em ocupar espaços livres para o lazer, pois não se consegue representar a si como sujeito emancipado.

Em pequenos espaços das cidades, pode-se encontrar para si algum lugar em que, em se possam destituir os muros e que possa transparecer a tentativa do surgimento da engenhosidade perdida e que, talvez, ainda beirem os sonhos daqueles buscam a emancipação. Para os educadores, isso seria a esperança de encontrar no 
processo formativo a diversidade de narrativas sobre a constituição do sujeito emancipado entre palavras e ações que se possam representar numa educação física que encontre brechas nos muros para realização da recreação como forma de recriar a si mesmo na educação do corpo. Isso, em última instância, constitui a formação do sujeito, numa sociedade democrática e, portanto, a sociedade sem muros, seria a posição do saber/fazer como elemento de acesso a todos que participam e usufruem da ciência e tecnologia como instrumento do pensamento e material para a melhoria da qualidade de vida de toda a população.

\section{REFERÊNCIAS}

ADORNO, Theodor. \& HORKHEIMER, Max. Dialética do esclarecimento: fragmentos filosóficos. Trad. Guido Antonio de Almeida. Rio de Janeiro: Jorge Zahar Editor, 1986.

CANETTI, Elias. Massa e Poder. Trad. Sérgio Tellaroli. São Paulo: Companhia das Letras, 1995 .

CHAUI, Marilena. A ideologia da competência. Belo Horizonte: Autêntica Editora, 2016.

FLORIANI, Dimas. Construção interdisciplinar do programa de pós graduação em meio ambiente e desenvolvimento da UFPR. In PHILIPPI Jr, Arlindo; NETO, Antonio J. Silva. Interdisciplinaridade em ciência, tecnologia \& inovação. Barueri: Manole, 2011.

FREUD, Sigmund. O Mal-Estar na Civilização (1930 [1929]). In: Obras

Completas. v. XXI. Trad. Jayme Salomão. Rio de Janeiro: Imago, 1996.

FOLHA. Conheça cinco cidades muradas pelo mundo. In: Folha de S. Paulo. Disponível em: https://www1.folha.uol.com.br/turismo/2018/02/conheca-cinco-cidadesmuradas-pelo-mundo.shtml. Acesso em: o9 jan 2018.

GLOBO. Ciclista é atropelado na Av. Paulista e tem braço amputado no acidente. In: G1. Disponível em: http://g1.globo.com/sao-paulo/noticia/2013/03/ciclista-e-atropelado-naavenida-paulista.html. Acesso em: 19 fev. 2018a.

GLOBO. Vidro de 2 km que vai separar a raia olímpica da USP da Marginal Pinheiros custará R $\$ 15$ milhões. In: G1. Disponível em: https://g1.globo.com/sao-paulo/noticia/vidro-de-2-km-quesepara-raia-olimpica-da-marginal-pinheiros-custara-r-15-milhoes.ghtml. Acesso em: 20 jan. 2018b.

GUATTARI, Félix. Caosmose. São Paulo: Ed. 34, 2000. 
LARROSA, Jorge. Tecnologias do eu e educação. In: SILVA, Tomaz Tadeu. O sujeito da educação. Petrópolis: Vozes, 1995.

MACHADO, Cassiano Elek. Urbanista se assusta com feudos de SP. Folha de S. Paulo, Caderno 3, 07 de junho de 1998, p. 6, 1998. Disponível em:

https://www1.folha.uol.com.br/fsp/cotidian/ffo7069817.htm. Acesso em: 22 jan.2018.

MARX, Karl. Introdução à crítica da economia política. In:

Contribuições à crítica da economia política. Trad. Maria Helena Barreiro Alves. $2^{a}$ ed. São Paulo: Martins Fontes, 1983.

MAUSS, Marcel. As técnicas corporais. In: Sociologia e

Antropologia. Trad. Mauro W. B. de Almeida. São Paulo, EPU/EDUSP, 2 v. 1974.

PARKER, Alan. Expresso da meia-noite (Midnight). USA, Columbia Tristar, 121 minutos, 1978.

PREFEITURA PRAIA GRANDE. Praia Grande. Disponível em:

http://www.praiagrande.sp.gov.br/praiagrande/index-.asp?cd pagina=77. Acesso em: 22 jan. 2018.

RANCIÈRE, Jacques. O mestre ignorante: cinco lições sobre a emancipação intelectual. Trad. Lílian do Valle. Belo Horizonte: Autêntica, 2002.

RANCIÈRE, Jacques. A partilha do sensível: estética e política. Trad. Mônica Costa Netto. São Paulo: EXO/Editora 34, 2009.

REDAÇÃO. Parceria com Prefeitura vai demolir muro da Raia Olímpica da USP. In: Jornal da USP. Disponível em: http://jornal.usp.br/universidade/parceria-comprefeitura-vai-demolir-muro-da-raia-olimpica-da-usp/. Acesso em: 20 jan. 2018.

SESC. Exposição sobre vida e obra do filósofo Vilém Flusser chega ao Sesc Ipiranga. In: eonline. Disponível em:

https://www.sescsp.org.br/online/artigo/11411 EXPOSICAO+SOBRE+VIDA+E+OB RA+DO+FILOSOFO+VILEM+FLUSSER+CHEGA+AO+SESC+IPIRANGA. Acesso em: 05 fev. 2018.

\section{SOBRE O AUTOR}

Graduado em Educação Física (Unesp - 1987), Especialista em Teorias e Métodos de Pesquisa (1989 - Unicamp). Mestre e Doutor em Educação (UNICAMP) Pós Doutor em Filosofia da Educação (2017 - USP) e Professor Titular da Universidade Federal de Itajubá - UNIFEI. e-mail: rrunifei@hotmail.com

\section{Tramitação:}

Recebido em: 25/02/2021.

Aprovado em:31/03/2021. 